\title{
Psychological Impact and Level of Knowledge Regard Covid19 among
} Institutionalized Elders

\section{Sabah Abo Elftouh ${ }^{1}$,Hend Reda Ali El-kest ${ }^{2}$, Amina Ahmed Wahba El-Salamony ${ }^{3}$ Omnya Sobhy Mohamad El-ayari ${ }^{4}$}

\author{
${ }^{1}$ Assistant Professor, ${ }^{2}$ Lecturer of Community Health Nursing. Faculty of Nursing, Tanta \\ University. \\ ${ }^{3,4}$ Lecturer, ${ }^{1,3,4}$ Psychiatric and Mental Health Nursing, Faculty of Nursing, Kafrelsheikh \\ University.
}

\section{Abstract}

Background: The coronavirus disease 2019 (COVID-19) was stated a pandemic by the WHO. All ages are at risk of COVID-19, but elders are more risky of COVID-19. The COVID-19 can be transmitted through droplets, respiratory secretions, and contact with contaminated surfaces and by contact with asymptomatic individuals. Aim: Thisstudy aimed to assess psychological impact and level of knowledge regard covid19 among institutionalized elders. Design: This study followed a descriptive cross-sectional study design. Setting: This study was conducted in two geriatric homes in Tanta city, El-Gharbia Governorate; Dar- Elsaada and Social care home for the elderly (Dar- Elagaza). These homes are affiliated to Ministry of Social Solidarity. Tools: The data of this study was collected using the following two tools: (I) COVID-19 rapid quantitative assessment tool and (II) Depression, Anxiety and Stress Scale - 21 Items (DASS-21). Results: The main results revealed that most of the studied elders had a fair level of knowledge regarding Covid19. Most of elders had mild levels of stress and depression but moderate level of anxiety. Conclusion: The present study assumed that the Pandemic of COVID-19 has been shown to affect elders' psychological status, by forced isolation and by concern about the virus, both. Recommendations: Providing psychological support services for the elders through various means of communication

Key words: Covid-19, psychological, knowledge, institutionalized, elders 


\section{Introduction}

In the twentieth century, the world has already threatened by more than a pandemic, the coronavirus disease 2019 represents one of the most critical challenges the world has yet opposed. ${ }^{1}$ The World Health Organization specified coronavirus disease 2019 (COVID-19) a pandemic on March 2020 due to high infection dissemination rate and the increased death rate all over the world. ${ }^{2}$ The infection of COVID-19 can be through respiratory secretions, droplets, contact with contaminated surfaces and contact with asymptomatic individuals. ${ }^{3}$

Where COVID-19 is a novel disease, there is a little knowledge on its risk factors. It is apparent that the elders have a higher risk of COVID-19 with a serious or fatal outcome. Many nations have an ageing population worldwide. The global category of older people over 65 years of age is probably grow from 11 percent in 2019 to 16 percent in 2050 . However, all ages are risky for COVID-19, elders face a greater risk of a serious illness. As, the elders face unique challenges; it is crucial that health care professionals identify and explain their particular needs. Unless providing special care, the elders may confront significant serious effects on their mental and psychological health. ${ }^{4,5}$
There are many reasons represent the elders as a risky group. First, advanced age itself causes multiple physical and mental health problems that increase vulnerability to infections and emotional distress. 5,6 Second, the elders, especially institutionalized, are vulnerable to social isolation even under normal circumstances, and in the current circumstances elders are prone to loneliness, stress and little social support. ${ }^{7}$ Third, if the elders faced a difficulty in accessibility to medications and health care facilities, they will be liable to suffer from deterioration in their physical and mental status. Finally, the repeated exposure to negative news about disease severity can increase anxiety, mood disorders and sleep instabilities; especially most media channels concentrate on the increased mortality rates of COVID-19 in elders. ${ }^{8,9}$

The reported COVID-19 symptoms until now are fever, dry cough, tiredness. The incubation period is from 1 to 14 days. ${ }^{10}$ In elders, as the fever response is weakened and further symptoms are concurrent with aging disorders, diagnosis is more challenging. Moreover, the effect of medications for aging disorders may contribute to the complicated effect of COVID-19 on elders. ${ }^{11}$

Elders' psychological status is affected in 
the pandemic in which fear is produced as a response against threatening events. Fear can be a key factor of many psychological disorders, so it needs great care and attention. $^{12,13}$ During COVID-19 pandemic, negative emotions like fear and anger rise the incidence of anxiety and stress in the elders which increase the occurrence of psychological instability. ${ }^{14,15}$

It is vital to help the elders accurately understanding COVID-19 risks and apply hard precautions for prevention. All countries have stressed broad knowledge related to application of public measures as quarantine application, social spacing, school closures and other preventive measures. The main knowledge about individual protection measures approved and recommended were the wearing of masks in enclosed spaces and on transportation, continuous repeated hand washing and sustaining a safe physical distance. ${ }^{16-18}$

Psychological protection efforts are very important as physical prevention effort and treatment of COVID-19, particularly between the elders. Hence, considering, suggesting, and applying psychological strategies for the elders management is an urgency significant duty. International efforts from the World Health Organization and the Center for Disease Control concentrated on providing numerous clinical assistance guides for mental health ${ }^{19}$ It is crucial to study the suitable strategies for maintaining the elders' emotional health during this pandemic such as utilizing the online technologies to provide and facilitate the availability of social support networks. ${ }^{20,21}$

\section{Significance of the problem}

COVID-19 is a new disease with high and rapid disseminated infection that significantly affects the elders physically and psychologically. According to $\mathrm{WHO}$ 2020 reported that eight out of ten COVID19 deaths have been in adults 65years old and olders. So, the nurse has a great role in helping elders to achieve the greatest possible level of knowledge about disease dimensions and prevention measures, provide social and psychological support to the elderly, helping for coping with this novel disease without exposure to infection.

\section{Aim of the study}

This study aimed to assess psychological impact and level of knowledge regard covid19 among institutionalized elders.

\section{Research questions}

1- Is there is impact of covid-19 on institutionalized elders' Psychological status?

2- What is the elders' knowledge level regarding covid-19? 


\section{Subjects and method}

\section{Research design}

The design used in this study is a descriptive cross-sectional study design.

\section{Research settings}

This study conducted in two geriatric homes in Tanta city, El-Gharbia Governorate; Dar- Elsaada and Social care home for the elderly (Dar- Elagaza). These homes are affiliated to Ministry of social solidarity. Dar- Elsaada provides service to male and female elders and consists of 45 rooms (95 beds). Social care home for the elderly (Dar- Elagaza) provides service to male and female elders and consists of 2 wards (100 beds).

\section{Subjects}

The study subjects constituted of 110 elders (convenience sample). They selected from the previous settings (65 elders from Dar- Elsaada and 45from Dar- Elagaza). The study subjects were fulfilling the following inclusion criteria:

- Aged 60 years and above

- Free from mental and psychiatric diseases

- Able to communicate and accept to participate in the study.

\section{Tools of data collection}

The study data was collected using the following three tools:

Tool I: - COVID-19 rapid quantitative assessment tool
It was a standardized questionnaire done by WHO, 2020. ${ }^{22}$ It consists of 17 items to assess knowledge about covid-19. Each statement has three responses: Complete answer was scored "two", incomplete answer was scored “one” while don't know answer was scored "zero". These scores were summed up and the total score was converted into a percent score and classified as:

- Poor knowledge level: < $60 \%$.

- Fair knowledge level: $60 \%$ - < $75 \%$.

- $\quad$ Good knowledge level: $\geq 75 \%$.

Tool II:- Depression, Anxiety and Stress Scale - 21 Items (DASS-21)

The Depression, Anxiety and Stress Scale 21 Items (DASS-21) were developed by Lovibond $1995^{23}$ it was designed to measure the emotional states of depression, anxiety and stress.It comprises three subscales that each has seven items.

- Depression (DASS 21- D), Anxiety (DASS 21- A), and Stress (DASS 21S)Each item is scored on a 4 -points likert scale ranging from 0 (never), 1 (sometimes), 2 (often) to 3 (almost always) . For the DASS-21, the following cut-off scores have been recommended for each subscale (subscale scores $=$ sum the score of each item to get a total score):- 


\begin{tabular}{|l|l|l|l|}
\hline & Depression & Anxiety & Stress \\
\hline Normal & $0-4$ & $0-3$ & $0-7$ \\
\hline Mild & $5-6$ & $4-5$ & $8-9$ \\
\hline $\begin{array}{l}\text { Modera } \\
\text { te }\end{array}$ & $7-10$ & $6-7$ & $10-12$ \\
\hline Severe & $11-13$ & $8-9$ & $13-16$ \\
\hline $\begin{array}{l}\text { Extrem } \\
\text { ely } \\
\text { severe }\end{array}$ & $14+$ & $10+$ & $17+$ \\
\hline
\end{tabular}

Data collection was supported by Biosociodemographic criteria(marital status, religious, level of education, income, residence length and number of sons) and Medical history (presence of chronic diseases, acute diseases, surgery and complication from any diseases).

\section{Method}

The following steps were followed in this study:

- Formal permission to conduct the study was obtained from dean of Tanta nursing faculty to the directors of DarElagaza and Dar El-saada Geriatric Homes.

\section{- Ethical considerations:}

- Oral consent was obtained from the elders after explanation of the aim of the study.

- Elders' privacy and data confidentiality were assured. Elders were reassured that the obtained information is confidential and used only for the study purpose.
- Elders' right to withdraw from the study at any time was emphasized.

- Every elderly was informed about the study purpose and importance at the beginning of the interview.

- The researchers, established on literature review, developed tool I (structured interview schedule).

- Tools of the study were translated into Arabic language

- A jury composed of five specialists in the psychiatric nursing and community health nursing field examined the validity of the study tools.

- Tools reliability was measured using Cronbach's Alpha test. Tool II (COVID-19 rapid quantitative assessment tool) reliability was 0.89 . Tool III (Depression, Anxiety and Stress Scale - 21 Items (DASS-21) reliability was 0.911 .

- A pilot study was carried out before embarking in the actual work to determine the clarity and applicability of the study tools and to recognize obstacles that might be confronted during collection of data. The pilot study conducted on 11 elders from the geriatric homes. Those elders excluded from the actual study subjects.

- Actual study: The study data collected through 3 months from June to August 2020. 


\section{Statistical analysis}

The data collected was structured, tabulated, coded and statistically analyzed using the computer statistical program SPSS software version 16.0. The present research was statistically described and analyzed using the following statistical measurements: frequency, percentage, arithmetic mean, standard deviation, linear coefficient of correlation and chi-square.

\section{Results}

Table 1 represents the studied elders' distribution by their socio-demographic and clinical criteria. This table shows that more than halfof the studied elders were male (55.5\%); their mean age was 67.73 +6.696 years. About half of the elders $(61.8 \%)$ were from the rural area and about one third of them $(41.8 \%)$ were illiterate. Regarding their clinical characteristic, half of studied elders have one year residence in geriatric home, $(46.4 \%)$ of them have physical disease, $(72.7 \%)$ were associated with complication.

Table 2 demonstrates the studied elders' distribution according to the level of knowledge regarding Covid19. Results revealed that most of the studied elders had a fair knowledge level regarding Covid19 $(66.4 \%)$ while $31.8 \%$ of the elders had a good level of knowledge regarding Covid19.
Table 3 shows the distribution of studied elders in relation to source of their knowledge concerning COVID-19. Results showed that the main source of data were T.V and social media (70\%, 64.5\%) respectively.

Table 4 illustrates the distribution of the studied elders regarding their level of stress, anxiety and depression, regarding level of anxiety the present study revealed that about one third of the studied elders $(35.5 \%)$ had moderate level of anxiety and (26.4\%) had sever level of anxiety. Concerning, level of stress, the majority $(86.3 \%)$ of studied elders had mild level of stress. As regards depression, most of the studied elders $(69.1 \%)$ had mild level of depression, while $(24.5 \%)$ of elders had moderate level of depression, and only $(6.4 \%)$ of them had sever level of depression.

Table 5 shows the correlation between depression, anxiety and stress and COVID19 knowledge Assessment of the studied elders. The results indicate statistically significant negative correlation only between elders' knowledge level regarding COVID-19, and their stresslevel $(\mathrm{P}=0.004)$ which indicated that, when the elders lever of knowledge concerning COVID-19 increased, their stress level decreased.

Table 6 illustrates comparison between depression, anxiety and stress and socio 
demographic criteria of the studied elders. The result revealed that, there were statistically significant relation between anxiety level and elders' sex where $P$ value $=.013$. Additionally, there were statistically significant relation between level of depression and elders' level of education as $\mathrm{P}$ value $=.037$. Also, there were statistically significant relation between level of stress, and presence of chronic disease where $\mathrm{P}$ value $=.005$.

Table 7 shows comparison between COVID-19 knowledge assessment and socio demographic criteria of the studied elders. The result revealed that there were statistically significant relations between elders' age, marital status, education level, residence and their knowledge level about COVID-19 where $P$ value $=, 000$. 
Table 1: Distribution of study subjects in relation to socio-demographic criteria

\begin{tabular}{|l|l|l|l|}
\hline \multirow{3}{*}{ Socio-demographic criteria $(\mathbf{N}=\mathbf{1 1 0})$} & $\mathbf{N}$ & $\mathbf{\%}$ \\
\hline \multirow{4}{*}{ Age } & Male & 61 & 55.5 \\
\cline { 2 - 4 } & Female & 49 & 44.5 \\
\hline \multirow{4}{*}{ Marital status } & $60-70$ & 79 & 71.8 \\
\cline { 2 - 4 } & $71-80$ & 25 & 22.7 \\
\cline { 2 - 4 } & $81-$ & 6 & 5.5 \\
\cline { 2 - 4 } & Mean SD: 67.73 & 6.696 & \\
\hline \multirow{3}{*}{ Residence } & Single & 73 & 66.4 \\
\cline { 2 - 4 } & Married & 16 & 14.5 \\
\cline { 2 - 4 } & Divorced & 13 & 11.8 \\
\cline { 2 - 4 } & Widow & 8 & 7.3 \\
\hline \multirow{4}{*}{ Education level } & Urban & 42 & 38.2 \\
\cline { 2 - 4 } & Rural & 68 & 61.8 \\
\hline \multirow{2}{*}{ Income } & Illiterate & 46 & 41.8 \\
\cline { 2 - 4 } & Elementary & 18 & 16.4 \\
\cline { 2 - 4 } & Secondary & 24 & 21.8 \\
\cline { 2 - 4 } & Bachelor & 22 & 20 \\
\hline \multirow{3}{*}{ Duration of residence } & Enough & 52 & 47.3 \\
\cline { 2 - 4 } & Not enough & 58 & 52.7 \\
\hline \multirow{2}{*}{ Chronic Physical disease } & $<6$ months & 24 & 21.8 \\
\cline { 2 - 4 } & 6 months- 1 year & 31 & 28.2 \\
\cline { 2 - 4 } & 1year- & 55 & 50 \\
\hline & Yes & 51 & 46.4 \\
\cline { 2 - 4 } & No & 59 & 53.6 \\
\hline
\end{tabular}

Table 2: Distribution of study elders in relation to COVID-19 knowledge Assessment Tool

\begin{tabular}{|l|l|l|}
\hline \multirow{2}{*}{ COVID-19 knowledge Assessment items } & \multicolumn{2}{|l|}{ Study subject $\mathrm{n}=110$} \\
\cline { 2 - 3 } & No & $\%$ \\
\hline Poor & 2 & 1.8 \\
\hline Fair & 73 & 66.4 \\
\hline Good & 35 & 31.8 \\
\hline
\end{tabular}

Table 3: Distribution of study elders in relation to source of data concerning COVID-19

\begin{tabular}{|l|l|l|l|l|}
\hline \multirow{2}{*}{ Source of data } & \multicolumn{2}{|c|}{ No } & \multicolumn{2}{c|}{ Yes } \\
\cline { 2 - 5 } & No. & \% & No. & \% \\
\hline Radio & 94 & 85.5 & 16 & 14.5 \\
\hline T.V & 33 & 30.0 & $\mathbf{7 7}$ & $\mathbf{7 0 . 0}$ \\
\hline Social media & 39 & 35.5 & $\mathbf{7 1}$ & $\mathbf{6 4 . 5}$ \\
\hline Hospital & 80 & 72.7 & 27 & 24.5 \\
\hline Family members & 63 & 57.3 & 47 & 42.7 \\
\hline Friends & 67 & 60.9 & 43 & 39.1 \\
\hline Doctor & 58 & 52.7 & 51 & 46.4 \\
\hline
\end{tabular}


Table 4: Comparison of the studied elders regarding their level of stress, anxiety and depression

\begin{tabular}{|l|l|l|l|}
\hline Variable & Level & N & \% \\
\hline \multirow{4}{*}{ Anxiety } & Mild & 33 & 30 \\
\cline { 2 - 4 } & Moderate & 39 & 35.5 \\
\cline { 2 - 4 } & Severe & 29 & 26.4 \\
\cline { 2 - 4 } & Extremely Severe & 9 & 8.2 \\
\hline \multirow{4}{*}{ Stress } & Mild & 95 & 86.3 \\
\cline { 2 - 4 } & Moderate & 14 & 12.7 \\
\cline { 2 - 4 } & Severe & 1 & 0.9 \\
\hline \multirow{4}{*}{ Depression } & Mild & 76 & 69.1 \\
\cline { 2 - 4 } & Moderate & 27 & 24.5 \\
\cline { 2 - 4 } & Severe & 7 & 6.4 \\
\hline
\end{tabular}

Table 5: Correlation between depression, anxiety and stress and COVID-19 knowledge Assessment of the studied elders

\begin{tabular}{|l|l|l|l|l|l|l|}
\hline \multicolumn{2}{|l}{} & \multicolumn{2}{l|}{ Anxiety } & \multicolumn{2}{l|}{ Stress } & \multicolumn{2}{l|}{ Depression } \\
\cline { 2 - 7 } & r. & P value & r. & P value & r. & P value \\
\hline $\begin{array}{l}\text { COVID-19 knowledge } \\
\text { Assessment }\end{array}$ & -.165 & .085 & $-.273 * *$ & .004 & -.137 & .154 \\
\hline
\end{tabular}

Table 6: Comparison between depression, anxiety, stress, and socio demographic criteria of the studied elders

\begin{tabular}{|c|c|c|c|c|c|c|}
\hline \multirow{3}{*}{$\begin{array}{l}\text { Socio } \\
\text { demographic } \\
\text { criteria }\end{array}$} & \multicolumn{6}{|c|}{ DASS } \\
\hline & \multicolumn{2}{|c|}{ Anxiety } & \multicolumn{2}{|l|}{ Stress } & \multicolumn{2}{|c|}{ Depression } \\
\hline & $X^{2}$ & $\begin{array}{l}\mathrm{P} \\
\text { value }\end{array}$ & $X^{2}$ & $\mathrm{P}$ value & $X^{2}$ & $P$ value \\
\hline Sex & 12.672 & $.013^{*}$ & 3.924 & .270 & 3.609 & .307 \\
\hline $\begin{array}{ll}\text { Level } & \text { of } \\
\text { education } & \end{array}$ & 13.099 & .362 & 7.642 & .571 & 17.846 & $.037 *$ \\
\hline Chronic disease & 1.484 & .830 & 12.862 & $.005 *$ & .702 & .873 \\
\hline
\end{tabular}

Table 7: Comparison between COVID-19 knowledge Assessment and socio demographic criteria of the studied elders

\begin{tabular}{|l|l|l|}
\hline \multirow{2}{*}{ Socio demographic criteria } & \multicolumn{2}{|l|}{ COVID-19 knowledge Assessment } \\
\cline { 2 - 3 } & $X^{2}$ & P value \\
\hline Age & 50.0 & $.000^{*}$ \\
\hline Marital status & 96.909 & $.000^{*}$ \\
\hline Education level & 21.636 & $.000^{*}$ \\
\hline Residence & 16.164 & $.000^{*}$ \\
\hline Chronic disease & 24.582 & $.000^{*}$ \\
\hline
\end{tabular}




\section{Discussion}

The worldwide spread of COVID-19 has triggered an ongoing public health crisis. At any age, COVID-19 can occur. The highest reported infections and deaths amongst the elders have, however, occurred because they are frailer physically and psychologically than other age groups. This research assesses how elders experience the COVID-19 pandemic in the targeted risk population and the way they perceive information; comply with guidelines and their feelings and how their mental health is impaired in the current situation. $^{1}$

The aim of the present study was to assess psychological impact and level of knowledge regard covid19 among institutionalized elders; the results of this study answered the research question.

In relation to the elders' knowledge level of Covid19, the findings of the present study presented that most of the studied elders had a fair knowledge level of Covid19. Such result can be relatively understood in the light of the availability of social media that provide sufficient information regarding COVID-19 at the same time elders have enough free time to follow all news about this pandemic. This result is congruent with Labbanet al. (2020), in their study that aimed to assess the awareness and knowledge level of covid
19 pandemic between Syrians founded that, the majority of the study subject knowledge level about COVID 19 was relatively fair. ${ }^{24}$

On the other hand, this result is contradicted with Bartolomeu et al. 2020, in his study that measures knowledge levels between elderly concerning COVID19 via a teleservice " who stated that; elderly participants had superficial knowledge of COVID-19, which means that their knowledge sources could be inadequate or that they hadn't sufficient ability to preserve information. ${ }^{25}$

Regarding, the studied elders' level of stress, anxiety and depression, the present study illustrated that, about one third of the studied elder had moderate level of anxiety. These results may be due to fear from vague, unknown disease. Also, may be related to negative effect of media that concentrate on the increased morbidity and death rates of COVID-19 in elders, and anxiety can be triggered through repeated exposure to rising numbers of deaths news. In this line, Huang and Zhaoin their study "Generalized anxiety disorder, depressive symptoms and sleep quality during COVID-19 outbreak in China: a web-based cross-sectional survey" revealed that elders had a significantly higher incidence of anxiety symptoms than Younger. ${ }^{26}$ 
Concerning, elder's level of depression the present study revealed that, most of suited elder had mild level of depression and stress. This result may be interpreted by the fact that, elders tend to be socially isolated more than younger people are. Therefore, they apply social distancing that in return reduce risk for infection. In addition, different significant life events in the past are also more probable, like potentially having lived through past epidemics or pandemics. Therefor; they had mild level of stress. Also, even in normal life style, the elderly are exposed to social isolation, and in this universal pandemic social isolation exaggerated in the all locations. This lack of outlets for social interaction and loneliness has been associated with perceived stress and worsen mood in the elderly.

In this concern, Nwachukwu et al. 2020 study of " COVID-19 Pandemic: agerelated differences in measures of stress, anxiety and depression in Canada" indicated that, the occurrence rates for moderate/high stress, were lowest among elders. This result is consistent with some previous studies that documented lower levels of stress, anxiety, and depressive symptoms in the elders. ${ }^{27}$

Moreover, the result of the present study indicates statistically significant negative correlation only between elders' knowledge level of COVID-19, and their stress level. This finding may be associated with presence of persistent stream of information concerning the pandemic that help them to learn more about the disease an how to protect self from infection that consequently decrease stress level.

These results were incongruent with Dubey et al. 2020, study about "knowledge of COVID-19 and its effect on emotion regulation and psychological flexibility founded significant differences between individuals' knowledge of COVID-19 regarding anxiety level, but there is no effect regarding stress and depression. ${ }^{28}$ Also, Roy et al. (2020) presented incongruous findings, as they found that a moderate knowledge level about corona virus was associated with a high anxiety level among their study sample. ${ }^{29}$

Regarding, relation between depression, anxiety and stress and socio demographic criteria of the studied elders. The result revealed statistically significant relation between level of anxiety and elders' sex because nearly half of study subject were female who are more liable to emotional disturbance and have more social burden. These results were similar to study done by Dubey et al. 2020, who reported that gender was an important anxiety indicator, with men showing a significantly greater level of anxiety than women. ${ }^{28}$ This result 
come in contrasts with earlier studies that have shown that women are more likely to feel anxious, and depressed during COVID-19. ${ }^{30-32}$

Also, there were statistically significant relation between level of stress, and presence of chronic disease. This result may be related to the WHO stronger instructions for elder people who have chronic diseases to take more rigid protective measures to protect them from COVID-19 as mortality rate and post COVID 19 complication were significantly high among these age group make them more susceptible to psychological distress during the pandemic. The results are consistent with other comparable research, who founded that, individuals suffering from chronic illness were more liable to have higher levels of stress. ${ }^{28,30,33}$

\section{Conclusion}

As stated by the results of this study, the most of the studied elders had a good knowledge level regarding Covid19. Most of elders had mild levels of stress and depression but moderate level of anxiety. It can be assumed that the COVID-19 Pandemic has been shown to affect elders' psychological status, by forced isolation and by concern about the virus, both.

\section{Recommendations}

- Providing psychological support services for the elders through various means of communication; provided through specialized persons.

- Increase social media channels to reduce feelings of social isolation and update elders' knowledge about the disease.

- Conducting awareness and educational campaigns about the covid-19 in geriatric homes through official authorities.

- Future studies will be needed to measure the covid-19 consequences on elders' emotional state.

\section{Acknowledgment}

The researchers would like to express gratitude, thanks and appreciations to the administration of the study settings for their support and cooperation. Also, great thanks for all elders who participated in this study for their acceptance sincerely in fulfilling the data for the study.

\section{References}

1. Kemenesi G, Kornya L, Tóth G, Kurucz K, Zeghbib S, Somogyi B, et al. Nursing homes and the elderly regarding the COVID-19 pandemic: Situation report from Hungary. Gero. Science. 2020; 1.

2. World Health Organization [WHO]. Naming the coronavirus disease (COVID-19) and the virus that causes it. [Cited 2020 June 8]. Available from: https://www.who.int/emergencies/diseas 
es/novel-coronavirus-2019/technical-

guidance/naming-the-coronavirus-

disease-(covid-2019)-and-thevirus-thatcauses-it.

3. Alves F, Samorinha C, Precioso, J. Knowledge, attitudes and preventive behaviors toward COVID-19: A study among higher education students in Portugal. Journal of Health Research.2020;

4. Gustavsson J, Beckman L. Compliance to recommendations and mental health consequences among elderly in Sweden during the Initial Phase of the COVID19 Pandemic-A Cross Sectional Online Survey. Int. J. Environ Res. Public Health. 2020; 17(15): 5380.

5. World Health Organization. Mental health of older adults. 2017. Available at: https://www.who.int/ newsroom/fact-sheets/detail/mental-healthof-older-adults. Accessed on 11 April 2020.

6. Andreas S, Schulz H, Volkert J, Dehoust M, Sehner S, Suling A, et al. Prevalence of mental disorders in elderly people: The European mental disease. ICF65 study. Br. J. Psychiatry. 2017; 210(2):125-31.

7. Armitage R, Nellums LB. COVID-19 and the consequences of isolating the elderly. Lancet Public Health. 2020; 5(5): 256.
8. Depoux A, Martin S, Karafillakis E, Preet R, Wilder-Smith A, Larson $\mathrm{H}$. The pandemic of social media panic travels faster than the COVID-19 outbreak. J. Travel Med. 2020; 27(3):31.

9. Philip J, Cherian V. Impact of COVID19 on mental health of the elderly. Int. J. Community Med Public Health 2020; 7(1): 2435-6.

10. World Health Organization [WHO]. Coronavirus overview. [Cited 2020 June 8]. Available from:https://www.who.int/healthtopics/coronavirus\#tab5tab_3.

11. Nikolich-Zugich J, Knox K, Rios C, Natt B, Bhattacharya D, Fain M. SARSCoV-2 and COVID-19 in older adults: What we may expect regarding pathogenesis, immune responses, and outcomes. GeroScience; 2020:1-10.

12. Lee $\mathrm{K}$, Jeong $\mathrm{C}$, Yim, J. Consideration of the Psychological and Mental Health of the Elderly during COVID-19: A theoretical review. International Journal of Environmental Research and Public Health. 2020; 17(21): 8098 .

13. Shin M, Liberzon I. The neurocircuitry of fear, stress, and anxiety disorders. Neuropsychopharmacology. 2010; 35(1): 169-191. 
14. Shigemura J, Ursano R, Morganstein C, Kurosawa M, Benedek M. Public responses to the novel 2019 coronavirus (2019-nCoV) in Japan: Mental health consequences and target populations. Psychiatry Clin. Neurosci. 2020; 74(1): 281-282.

15. Briguglio $\mathrm{M}$, Giorgino $\mathrm{R}$, Dell'Osso B, Cesari M, Porta M, Lattanzio F, et al. Consequences for the elderly after COVID-19 isolation: FEaR (Frail Elderly amid Restrictions). Front. Psychol. 2020; 11: 565052.

16. Tang Z, Wang J, Liang Q, Zheng X, Meng Y, Shu B, et al. Discussion on the prevention and treatment of COVID-19 pneumonia in the elderly from the regulation of "kidney essence" status. Tianjin J. Trad. Chin. Med. 2020; 37(1): 125-131.

17. Haug N, Geyrhofer L, Londei A, Dervic E, Desvars-Larrive A, Loreto V, et al. Ranking the effectiveness of worldwide COVID-19 government interventions. Nature human behaviour, 1-10. Armitage, R.; Nellums, L.B. COVID-19 and the consequences of isolating the elderly. Lancet Public Health. 2020; 5(1): e256.

18. Shadmi E, Chen Y, Dourado I, FaranPerach I, Furler J, Hangoma P, et al. Health equity and COVID-19: Global perspectives. International Journal for Equity in Health. 2020;19(1): 1-16.

19. Folkman S, Lazarus S. An analysis of coping in a middle-aged community sample. J. Health Soc. Behav. 1980; 21(1): 219-239.

21. Armitage R, Nellums B. COVID-19 and the consequences of isolating the elderly. The Lancet Public Health. 2020; 5(5): e256.

21. World Health Organization. COVID19 Preparedness and response - 2020. Available from: WwW.who.int > covid19-rcce-guidancefinal-brand

22. Lovibond H, Lovibond F.Manual for the depression anxiety andstressscales. $2^{\text {nd }}$ Ed. Sydney: Psychology Foundation. 1995.

23. Labban L, Thallaj N, Labban A. Assessing the level of awareness and knowledge of COVID 19 Pandemic among Syrians. Arch Med. 2020; 12(2): 8

24. De Lima Filho F, Bessa S, Fernandes T, Da Silva Patrício F, De Oliveira Alves N, Da Costa Cavalcanti, A. (). Knowledge levels among elderly people with Diabetes Mellitus concerning COVID-19: An educational intervention via a teleservice. Acta Diabetologica. 2020;1-6.

25. Huang Y, Zhao N. Generalized anxiety disorder, depressive symptoms 
and sleep quality during COVID-19 outbreak in China: A web-based crosssectional survey. Psychiatr. Res. Neuroimaging. 2020; 288(1): 112954.

26. Nwachukwu I. 2020,17(17), 6366; COVID-19 Pandemic: Age-Related Differences in Measures of Stress, Anxiety and Depression in Canada

27. Dubey N, Podder P, Pandey D. Knowledge of COVID-19 and its influence on mindfulness, cognitive emotion regulation and psychological flexibility in the Indian Community. Front. Psychol. 2020; 11(1):589365. Doi: 10.3389/fpsyg.2020.589365.

28. Roy D, Tripathy S, Kar K, Sharma N, Verma K, Kaushal V. Study of knowledge, attitude, anxiety and perceived mental healthcare need in Indian population during COVID-19 pandemic. Asian J. Psychiatr. 2020; 51(1):102083. Doi: 10.1016/j.ajp.2020.102083

29. Ebrahim H, Saif Q, Buheji M, AlBasri N, Al-Husaini A. COVID-19 information-seeking behavior and anxiety symptoms among parents. OSP J. Health Car. Med. 2020; 1: HCM-1-105. 30. Liu N, Zhang, Wei C, Jia Y, Shang Z, Sun L, et al. Prevalence and predictors of PTSS during COVID-19 outbreak in
China hardest-hit areas: Gender differences matter. Psychiatry Res. 2020; 287(1): 112921.

31. Özdin, S, BayrakÖzdin Ş. Levels and predictors of anxiety, depression and health anxiety during COVID-19 pandemic in Turkish society: The importance of gender. Int. J. Soc. Psychiatry. 2020; 66(1), 504-511.

32. Bohlmeijer E, Prenger R, Taal E, Cuijpers P. The effects of mindfulnessbased stress reduction therapy on mental health of adults with a chronic medical disease: A meta-analysis. J. Psychosom. Res. 2010; 68(1): 539-544. 